\title{
Eosinophilic Gastroenteritis Presenting with Severe Anemia and Near Syncope
}

\author{
Nneka Ekunno, DO, MPH, Kirk Munsayac, DO, Allen Pelletier, MD, \\ and Thad Wilkins, MD
}

Eosinophilic gastrointestinal disorders or eosinophilic digestive disorders encompass a spectrum of rare gastrointestinal disorders that includes eosinophilic esophagitis, eosinophilic gastroenteritis, and eosinophilic colitis. Eosinophilic gastroenteritis is a rare inflammatory disease characterized by eosinophilic infiltration of the gastrointestinal tract. The clinical manifestations include anemia, dyspepsia, and diarrhea. Endoscopy with biopsy showing histologic evidence of eosinophilic infiltration is considered definitive for diagnosis. Corticosteroid therapy, food allergen testing, elimination diets, and elemental diets are considered effective treatments for eosinophilic gastroenteritis. The treatment and prognosis of esinophilic gastroenteritis is determined by the severity of the clinical manifestations. We describe a 24-year-old woman with eosinophilic gastroenteritis presenting as epigastric pain with a history of severe iron deficiency anemia, asthma, eczema, and allergic rhinitis, and we review the literature regarding presentation, diagnostic testing, pathophysiology, predisposing factors, and treatment recommendations. (J Am Board Fam Med 2012;25:913-918.)

Keywords: Case Reports, Eosinophilic Gastroenteritis, Gastrointestinal Disorders

A 24-year-old nulliparous African-American woman was admitted after an episode of near syncope associated with 2 days of fatigue and dizziness. She reported gradual onset of dyspepsia over 2 to 3 months. She denied nausea, vomiting, menorrhagia, polymenorrhea, diarrhea, hematemesis, melena, or hematochezia. Her medical history was significant for allergic rhinitis, eczema, and asthma. Her surgical history was negative. She denied using tobacco or illicit drugs. She drank approximately 1 to 2 beers per month. Her family history was significant for a father with asthma and hypertension and a mother with hypertension. Her medications included inhaled fluticasone, an albuterol metered-dose inhaler, a Flovent inhaler, loratadine, and ranitidine.

This article was externally peer reviewed.

Submitted 14 September 2011; revised 12 December 2011; accepted 19 December 2011.

From the Department of Family Medicine, Georgia Health Sciences University, Augusta, GA.

Funding: none.

Conflict of interest: none declared.

Corresponding author: Thad Wilkins, MD, Department of Family Medicine, Medical College of Georgia, Georgia Health Sciences University, 1120 Fifteenth Street, HB-4032, Augusta, GA 30912 (E-mail: twilkins@georgiahealth.edu).
During examination, her height was 62 inches, weight $117 \mathrm{lb}$, and body mass index $21.44 \mathrm{~kg} / \mathrm{m}^{2}$. Her heart rate was 111 beats per minute, blood pressure $121 / 57 \mathrm{~mm} \mathrm{Hg}$, respiratory rate 20 breaths per minute, and oral temperature of $98.6^{\circ} \mathrm{F}$. She appeared acutely ill and lethargic. She was oriented to person, place, and time. She had pallor of the conjunctiva. Cardiovascular, respiratory, musculoskeletal, and neurological examinations were normal. Her abdomen was soft and nontender, without organomegaly. Rectal examination revealed brown stool that was hemoccult negative.

Initial laboratory tests revealed a hemoglobin level of $5.1 \mathrm{~g} / \mathrm{dL}$ (normal range, $12.0-16.0 \mathrm{~g} / \mathrm{dL}$ ), a hematocrit level of $17.1 \%$ (normal, $37.0 \%$ to $47.0 \%$ ), a mean corpuscular volume of $66.9 \mathrm{fL}$ (normal, 80.0-98.0 fL), a red blood cell distribution width of $31.1 \% \mathrm{~F}$ (normal, $11.5-18.0 \% \mathrm{~F})$, and a platelet count of $921,000 / \mathrm{mm}^{3}$

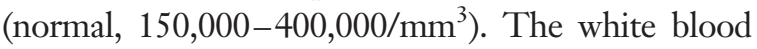
cell differential included $82 \%$ neutrophils, $5 \%$ lymphocytes, $5 \%$ monocytes, $6 \%$ eosinophils, and $2 \%$ basophils. Human chorionic gonadotropin test was negative. Ferritin level was $2.3 \mathrm{ng} / \mathrm{mL}$ (normal, $10.00-291.00 \mathrm{ng} / \mathrm{mL}$ ), iron level was $11 \mathrm{mcg} / \mathrm{dL}$ (normal, 50-175 $\mu \mathrm{g} / \mathrm{dL}$ ), and total iron-binding capacity was $404 \mu \mathrm{g} / \mathrm{dL}$ (normal, 250-450 $\mu \mathrm{g} / \mathrm{dL}$ ). 
International normalized ratio was 1.0. She was admitted for symptomatic anemia and transfused with 4 $\mathrm{U}$ packed red blood cells. After the transfusion, her hemoglobin level was $12 \mathrm{~g} / \mathrm{dL}$. The patient was discharged in stable condition and was seen 1 week later by a hematologist, who confirmed the diagnosis of severe iron-deficiency anemia, and oral iron replacement therapy was initiated.

The patient returned 1 month later, complaining of epigastric pain, nausea, vomiting, and diarrhea. She reported several days of watery diarrhea and complained of anorexia. She reported one episode of hematemesis. Stool samples were sent for culture, gram stain, and examination for ova and parasites, and the stool studies were negative. After several days, abdominal pain persisted and omeprazole was added to the treatment regimen. An esophagogastroduodenoscopy was performed, which showed diffusely erythematous mucosa with an atrophic and nodular gastric mucosa extending into the first portion of the duodenum. Gastric biopsies were obtained for Helicobacter pylori and a pathology review. Omeprazole and ranitidine were continued. Gastric and duodenal biopsy results demonstrated diffuse glandular atrophy with dense eosinophilic infiltration (Figure 1). Pathology results were not consistent with celiac disease. She began taking oral prednisone with a slow taper over 6 weeks. A computed axial tomography scan of the abdomen and pelvis was obtained and was normal, without evidence of obstruction. She was referred to allergy/immunology. Subsequent immunoglobulin testing revealed a total immunoglobulin (Ig) E level of $1997 \mathrm{kU} / \mathrm{L}$ (reference range, 0.00-148.00 kU/L). Specific IgE subset testing showed elevated levels of IgE to eggs, milk, corn, oats, rice, wheat, peanuts, and soybeans. She began an elimination diet based on IgE testing but was noncompliant. She followed up after completing the course of prednisone, and her abdominal pain, diarrhea, nausea, and vomiting had completely resolved. Her hemoglobin remained stable.

\section{Discussion}

Eosinophilic gastrointestinal disorders or eosinophilic digestive disorders (EGIDs) encompass a spectrum of rare gastrointestinal disorders that includes eosinophilic esophagitis, eosinophilic gastroenteritis, and eosinophilic colitis. ${ }^{1}$ These conditions are increasingly being recognized despite the varying clinical presentation, likely as a result of in-
Figure 1. Histology of gastric biopsies showing eosinophilic infiltration. A: The biopsy consists of gastric antral type mucosa that is heavily infiltrated by eosinophils. B: Many high-power fields contain more than 50 eosinophils. In addition, esinophils infiltrate the glandular epithelium, and many of the glands appear damaged and exhibit reactive atypia. C: In addition, there appears to be loss of a significant number of glands. This may explain the atrophic appearance noted during endoscopic examination. The histologic features are characteristic of eosinophilic gastroenteritis.

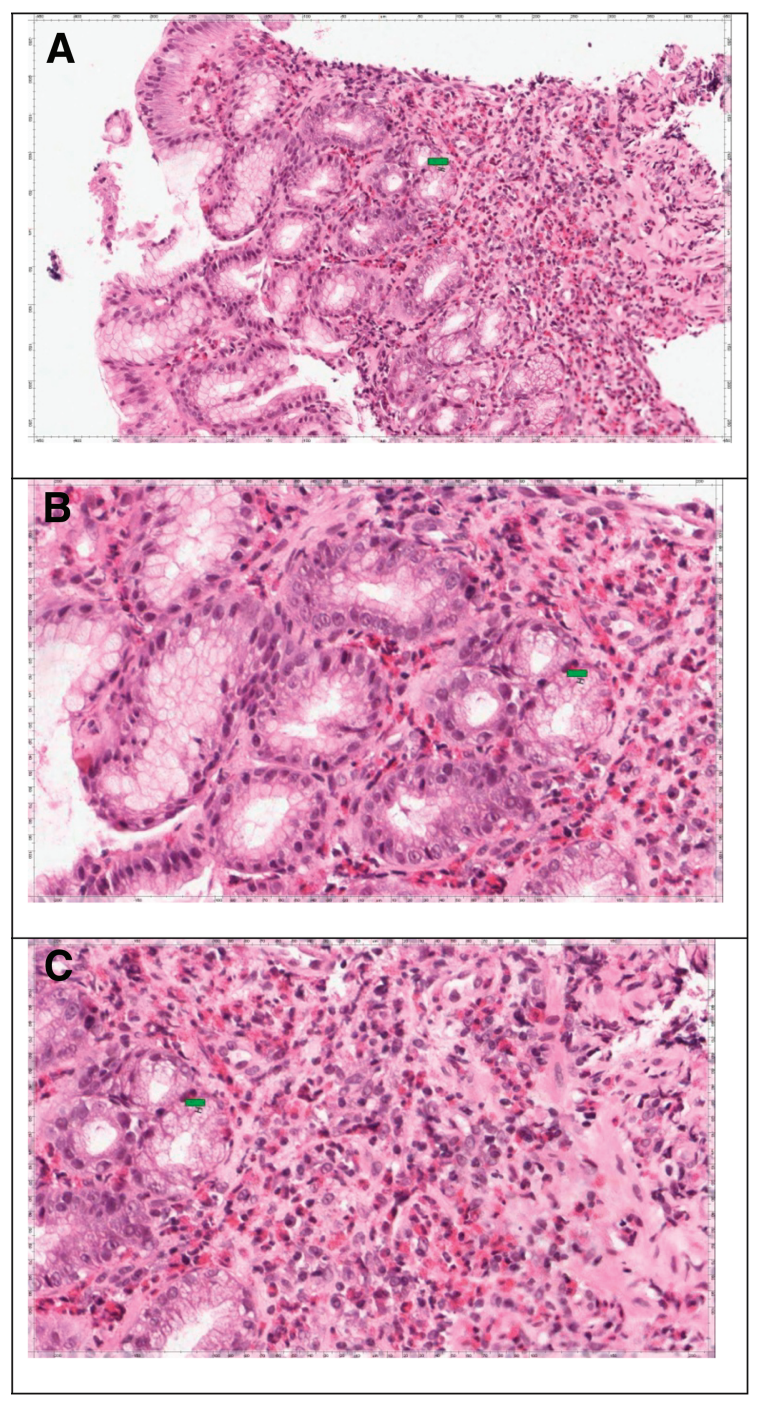

creased diagnostic testing with esophagogastroduodenoscopy and colonoscopy, both with biopsy. Under normal, nonpathologic conditions, the gastrointestinal tract is the only nonhematopoietic organ to contain eosinophils, and the cecal and appendiceal regions have the highest concentrations. ${ }^{2}$ It is postulated that exposure of the gastrointes- 
Table 1. Classification of Eosinophilic Gastrointestinal Diseases

\begin{tabular}{|c|c|c|}
\hline Туре & Symptoms & Treatment \\
\hline Mucosal & $\begin{array}{l}\text { Anemia from iron deficiency or occult fecal blood loss, protein-losing enteropathy, } \\
\text { and malabsorption, peripheral edema } \\
\text { Most frequent type }\end{array}$ & $\begin{array}{l}\text { Elimination diet } \\
\text { Cromoglycate } \\
\text { Ketotifen } \\
\text { Glucocorticosteroids } \\
\text { Azathioprine }\end{array}$ \\
\hline Submucosal & $\begin{array}{l}\text { Bowel wall thickening results in obstructive signs (colicky pain, nausea, vomiting) } \\
\text { At risk for bowel obstruction }\end{array}$ & $\begin{array}{l}\text { Montelukast } \\
\text { Imatinib mesylate } \\
\text { Omalizumab }\end{array}$ \\
\hline Serosal & $\begin{array}{l}\text { Associated with ascites, bloating, high peripheral eosinophilia, peritonitis } \\
\text { Rarest form }\end{array}$ & $\begin{array}{l}\text { Histamine } 2 \text { receptor blockers } \\
\text { Proton pump inhibitors }\end{array}$ \\
\hline
\end{tabular}

Adapted from Refs. 6-9.

tinal mucosa to antigens promotes a Th-2-mediated immune response. ${ }^{3}$ Th-2 cells produce interleukin (IL)-4, IL-5 and IL-3 and promote the production of eosinophils as well as IgE. ${ }^{3}$

Eosinophilic esophagitis is the most commonly recognized EGID; most often it is seen in white men and presents with symptoms of gastroesophageal reflux disease. Eosinophilic gastroenteritis is a condition in which eosinophils infiltrate either the stomach or small bowel, and approximately 50\% may have atopic disorders, food intolerances, or food allergies. ${ }^{4}$ Eosinophilic colitis is a rare condition that causes colonic eosinophilia, and patients typically present with abdominal pain, diarrhea, and weight loss. ${ }^{4}$ The clinical manifestations of EGIDs depend on which layer and which bowel segments are predominantly involved. EGID is classified into mucosal, submucosal, and serosal disease $^{5}$ (see Table 1). Except for the serosal form, in which $75 \%$ of the patients are women aged 40 years or older, eosinophilic gastroenteritis is a predominantly male disorder that affects children as well as adults. $^{10}$

\section{Literature Search Strategy}

We searched PubMed, Ovid, and Web of Knowledge using search terms eosinophilic gastroenteritis and eosinophilic gastrointestinal disorders but excluded the search terms eosinophilic esophagitis, eosinophilic colitis, and allergic gastroenteropathy. We found no randomized controlled trials or systematic review articles but found approximately 300 case reports and case series.

\section{Clinical Symptoms}

The most common symptoms of eosinophilic gastroenteritis include abdominal pain (90\%), diarrhea $(60 \%)$, vomiting $(60 \%)$, nausea $(50 \%)$, and abdominal distension (50\%). ${ }^{11,12}$ Eosinophilic gastroenteritis affects all races and age groups, although in adults it usually presents during the third to fifth decades of life. ${ }^{13}$ It is necessary to rule out other causes of eosinophilia, such as drug reaction, parasitic infection, and cancer. ${ }^{14}$ The differential diagnosis of eosinophilic gastroenteritis includes disorders of eosinophilic infiltration, collagen vascular disorders,

Table 2. Differential Diagnosis for Eosinophilic Gastroenteritis

\begin{tabular}{ll}
\hline Systemic disorders & $\begin{array}{l}\text { Vasculitis: Churg-Strauss syndrome or polyarteritis nodosa } \\
\text { Connective tissue disease: scleroderma, dermatomyositis, eosinophilia-myalgia syndrome } \\
\text { Others: idiopathic hypereosinophilia, mastocytosis, histocytosis X, nonlipid histiocytosis, eosinophilic } \\
\text { granuloma } \\
\text { Carcinomas, lymphomas }\end{array}$ \\
$\begin{array}{l}\text { Tumors } \\
\text { Intestinal }\end{array}$ & $\begin{array}{l}\text { Intestinal perforation } \\
\text { Food allergies }\end{array}$ \\
Cow milk enteropathy \\
Parasites & Parasites (Ancylostoma caninum, giardiasis, strongyloidosis, other zoonoses) \\
Toxins & Drugs (aspirin, sulfonamides, penicillin, cephalosporin, carbamazepine, azathioprine, L-tryptophan, \\
& and gold salts)
\end{tabular}

Adapted from Ref. 2. 
Figure 2. Algorithm for the workup and treatment of eosinophilic gastroenteritis. ANA, antinuclear antibody.

Clinical suspicion
for eosinophilic
gastroenteritis.

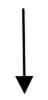

Laboratory testing

includes complete blood

count with differential,

sedimentation rate,

rheumatoid factor,

Labs are diagnostic

ANA, stool studies, stool

for $C$. difficile, urinalysis,

ferritin, iron level, B12

level, and folate level.

Labs are nondiagnostic.

Consider imaging

including

ultrasound or

computed axial

Imaging shows perforation

or obstruction.

tomography scan of

abdomen and

pelvis.

$\downarrow$

Obtain EGD

Biopsy negative for

eosinophilic infiltration.

with biopsy.

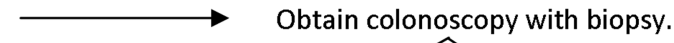
eosinophilic infiltration.

Begin elimination diet and allergy testing.

Consider allergy-

immunology

consultation.

Symptoms persist.

Start prednisone 20

$40 \mathrm{mg}$ a day for 4

weeks.

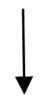

Consider budesonide,

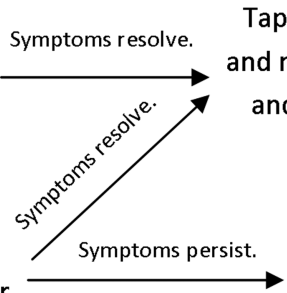

Taper medications

and monitor for signs

and symptoms of

recurrence.

Obtain gastroenterology and allergy-

sodium cromoglycate, or montelukast. 
inflammatory bowel disease, malignancies, medications (eg, enalapril), and hypereosinophilic syndrome (Table 2).

\section{Diagnostic Testing}

A clinical history of other atopic conditions such as asthma, atopic dermatitis, and food and environmental allergies should heighten suspicion for eosinophilic gastroenteritis. Peripheral eosinophilia and elevated $\operatorname{IgE}$ are suggestive findings of initial laboratory testing. ${ }^{3,15}$ Additional testing may include allergy evaluation by skin and serum radioallergosorbent tests, albumin and protein levels, $\alpha-1$ antitrypsin levels, and analysis of ascitic fluid for eosinophils. ${ }^{1}$

Radiologic tests are nonspecific but may show varying degrees of inflammation such as mucosal thickening and irregularity. The most common computed tomography finding is nodular and irregular folds and thickening in the distal stomach and proximal small bowel. ${ }^{16}$ Abdominal ultrasound may detect ascites. Definitive diagnosis requires esophagogastroduodenoscopy with biopsy showing histologic evidence of eosinophilic infiltration (see Figure 2).

\section{Therapeutic Options}

Food allergy testing and elimination and elemental diets should be considered and often are performed before a trial of corticosteroids. Spontaneous remission may occur in up to $40 \%$ of patients. ${ }^{17}$ In pediatric cases of eosinophilic gastroenteritis, elimination diets have been beneficial, in some cases without a need for additional treatment, and may describe a subset of patients with allergic eosinophilic gastroenteritis. ${ }^{7,18,19}$ Corticosteroids are the mainstay of therapy, and most patients have symptomatic response. Symptom relief usually occurs within a few weeks of the initiation of treatment. ${ }^{16,20}$ Treatment with histamine $\mathrm{H}-1$ receptor antagonists or mast cellstabilizing drugs (eg, cromoglycate), has been described in previous studies and may be considered in patients who do not respond to or cannot tolerate corticosteroids. Montelukast, a selective and competitive leukotriene receptor antagonist, may be considered as a corticosteroid-sparing agent. ${ }^{16,21}$ Consultation with an allergist/immunologist or a gastroenterologist should be considered for patients with persistent symptoms despite an adequate trial of corticosteroids. Therapy with immunomodulators (eg, azathio- prine) or chemotherapeutic agents (eg, imatinib) may be considered in patients with severe and unremitting symptoms. The natural course of the disease is uncertain and relapses are frequent; therefore, patients should be monitored after therapy has been initiated to reassess for symptom recurrence or complications. Surgery usually is not necessary but is sometimes needed in cases of intestinal obstruction or perforation.

\section{Conclusions}

Additional studies are needed to follow the natural history of this disorder. Randomized, control trials are needed to assess the effectiveness and safety of pharmacological and nonpharmacological therapies for eosinophilic gastroenteritis. Eosinophilic gastroenteritis is a chronic gastrointestinal disease with a variety of clinical presentations. A high degree of clinical suspicion is needed for accurate diagnosis. Oral corticosteroids are the mainstay of therapy.

\section{References}

1. Khan S, Orenstein SR. Eosinophilic gastroenteritis: epidemiology, diagnosis and management. Paediatr Drugs 2002;4:563-70.

2. Oh HE, Chetty R. Eosinophilic gastroenteritis: a review. J Gastroenterol 2008;43:741-50.

3. Shifflet A, Forouhar F, Wu GY. Eosinophilic digestive diseases: eosinophilic esophagitis, gastroenteritis, and colitis. J Formos Med Assoc 2009;108:83443.

4. Alfadda AA, Storr MA, Shaffer EA. Eosinophilic colitis: epidemiology, clinical features, and current management. Therap Adv Gastroenterol 2011;4: 301-9.

5. Yun MY, Cho YU, Park IS, Choi SK, Kim SJ, Shin SH, Kim KR. Eosinophilic gastroenteritis presenting as small bowel obstruction: a case report and review of the literature. World J Gastroenterol 2007;13: $1758-60$.

6. Siewert E, Lammert F, Koppitz P, Schmidt T, Matern S. Eosinophilic gastroenteritis with severe protein-losing enteropathy: successful treatment with budesonide. Dig Liver Dis 2006;38:55-9.

7. Yan BM, Shaffer EA. Primary eosinophilic disorders of the gastrointestinal tract. Gut 2009;58:721-32.

8. Fenoglio LM, Benedetti V, Rossi C, et al. Eosinophilic gastroenteritis with ascites: a case report and review of the literature. Dig Dis Sci 2003;48:101320.

9. Klein NC, Hargrove RL, Sleisenger MH, Jeffries GH. Eosinophilic gastroenteritis. Medicine (Baltimore) 1970;49:299-319. 
10. Straumann AM. Idiopathic eosinophilic gastrointestinal diseases in adults. Best Pract Res Clin Gastroenterol 2008;22:481-96.

11. Siewart E, Lammert F, Koppitz P, Schmidt T, Matern S. Eosinophilic gastroenteritis with severe protein-losing enteropathy: successful treatment with budesonide. Dig Liver Dis 2006;38:55-9.

12. Lee CM, Changchien CS, Chen PC, et al. Eosinophilic gastroenteritis: 10 years experience. Am J Gastroenterol 1993;88:70-4.

13. Lynbaek SA, Adamsen S, Aru A, Bergenfeldt M. Recurrent acute pancreatitis due to eosinophilic gastroenteritis. case report and literature review. JOP 2006;7:211-7.

14. Wolpin BM, Weller PF, Katz JT, Levy BD, Loscalzo J. Clinical problem solving. The writing on the wall. N Engl J Med 2009;361:1387-92.

15. Madhotra R, Eloubeidi MA, Cunningham JT, Lewin D, Hoffman B. Eosinophilic gastroenteritis masquerading as ampullary adenoma. J Clin Gastroenterol 2002;34:240-2.

16. Lin $\mathrm{HH}, \mathrm{Wu} \mathrm{CH}, \mathrm{Wu} \mathrm{LS}$, Shyu RY. Eosinophilic gastroenteritis presenting as relapsing severe abdom- inal pain and enteropathy with protein loss. Emerg Med J 2005;22:834-5.

17. de Chambrun GP, Gonzalez F, Canva JY, et al. Natural history of eosinophilic gastroenteritis. Clin Gastroenterol Hepatol 2011;9:950-6 e1.

18. Chehade M, Magid MS, Mofidi S, NowakWegrzyn A, Sampson HA, Sicherer SH. Allergic eosinophilic gastroenteritis with protein-losing enteropathy: intestinal pathology, clinical course, and long-term follow-up. J Pediatr Gastroenterol Nutr 2006;42:516-21.

19. Justinich C, Katz A, Gurbindo C, et al. Elemental diet improves steroid-dependent eosinophilic gastroenteritis and reverses growth failure. J Pediatr Gastroenterol Nutr 1996;23:81-5.

20. Khan S, Orenstein SR. Eosinophilic gastroenteritis. Paediatr Drugs 2002;4:563-70.

21. Schwartz DA, Pardi DS, Murray JA. Use of montelukast as steroid-sparing agent for recurrent eosinophilic gastroenteritis. Dig Dis Sci 2001;46:178790 . 